\title{
Infrared Study of Some Structural Changes in Natural Rubber During Vulcanization*
}

\author{
Frederic J. Linnig and James E. Stewart ${ }^{1}$
}

\begin{abstract}
A knowledge of the structure of vulcanized rubber is essential to the interpretation of vulcanization and oxidation studies and the physical properties of the material.

In the present work an infrarod study has been made of structures resulting from a number of different methods of vulcanization. Sulfur vulcanizates show the presence of a shifted double bond, originally observed by Sheppard and Sutherland. The presence of conjugated double bonds is also indicated. Accelerators such as tetramethylthiuram disulfide and zine dibutyl dithiocarbamate increase the rate of the double-bond shift and reduce the amount of conjugated double bonds. Neither the double-bond shift nor conjugation is observed as a result of vulcanization with tetramethylthiuram disulfide alone, hydrogen sulfide and sulfur dioxide (Peachey process), a peroxide, or gamma rays. These result in a possible decrease in carbonyl structures, and in the case of the last three, possible increased absorption due to $\mathrm{OH}$ and ionized carboxyl groups.

Apparently, the double-bond shift and conjugation are primarily phenomena related to the use of elemental sulfur. The other vulcanization systems studied evidently involve different mechanisms. An implication of the present work is that there may be a relationship between the reported ease of oxidation of sulfur vulcanizates, accelerated vulcanizates, and sulfurless vulcanizates (tetramethylthiuram disulfide alone), which decreases in the order named, and the probable amount of conjugation in the compound, which decreases in the same order.
\end{abstract}

\section{Introduction}

In order to elucidate structural changes occurring during vulcanization, Sheppard and Sutherland [35, $36]^{2}$ studied the infrared spectra, between 2 and $-18 \mu$, of accelerated and unaccelerated sulfur vulcanizates. In the $6.0 \mu$ region they found little evidence of changes in absorption due to double bonds. A band at $10.4 \mu$ was attributed to trans hydrogens adjacent to a carbon-to-carbon double bond resulting from a shift of the double bond normally present in unvulcanized rubber. This band had been discovered earlier by Sears [31]. Salomon and Van der Schee [28] have confirmed, essentially, the findings of Sheppard and Sutherland $[35,36]$. The results of infrared studies of vulcanization through 1949 are summarized by Mann [25].

The earlier siudies had been made using singlebeam instruments. The double-beam instruments now available are, of course, capable of greater definition in the critical double-bond region near $6.0 \mu$ and in other regions where there occurs intense atmospheric absorption. For these reasons, some of the studies of these workers were repeated using a double-beam instrument. Since the work on accelerated and unacceleratea sulfur vulcanizates proved fruitful, additional studies were made of other vulcanization systers including those involving tetramethylthiuram disulfide (TMTD) alone, a peroxide, gamma rays, and sulfur dioxide and hydrogen sulfide (Peachey process).

*This work was presented at the 70th meeting of the Division of Rubber Chemistry of the American Chemical Society, Atlantic City, N. J., September 1956. A portion of this work was performed as part of a research project sponsored by the National Science Foundation in connection with the Government Synthetic Rubber Program.

1 Present address: Beckman Instruments, Inc., Fullerton, Calif.

2 Figures in brackets indicate the literature references at the end of this paper.
Some spectra were also obtained in the region between 15 and $40 \mu$ using a cesium bromide prism to determine the existence of bands in this region, which might be due to $\mathrm{C}-\mathrm{S}$ and $\mathrm{S}-\mathrm{S}$ linkages.

In order to support the work on sulfur vulcanization a study was made of the squalene-sulfur system, and chemical evidence was obtained for one of the infrared interpretations.

\section{Experimental Procedure}

Most of the infrared spectra were obtained with a Perkin-Elmer model 21 double-beam spectrophotometer equipped with a sodium chloride prism for the range between 2 and $15 \mu$, and a cesium bromide prism for the range between 15 and $40 \mu$. An attachment ordinarily used to hold small $\mathrm{KBr}$ disks was employed in most of this work. With this attachment, the specium is inserted through the opening in the instrument cover to a position of minimum beam size, thus making possible the use of specimens as small as $3 / 8$ in. in diameter, which in some cases were all that could be obtained.

Additional measurements at higher resolution were made on certain bands using a Beckman IR-4 spectrophotometer equipped with two sodium chloride prisms. Some of the complete spectra were also obtained with this instrument.

Specimens of unvulcanized rubber were prepared by evaporating to dryness natural rubber latex which had been diluted with water sufficiently to give a film. of satisfactory thickness. In addition, specimens of unvulcanized smoked sheet, crepe rubber, or purified rubberwere prepared by hot-pressing the material between sheets of aluminum foil with the aid of a Carver press. It was found that a pressure of about 1,000 to 4,000 $\mathrm{lb} /$ in. $^{2}$ was sufficient to produce a specimen of suitable thickness, i. e., somewhere between 0.05 and 0.12 
$\mathrm{mm}$. The samples vulcanized by the Peachey process or by treatment with gamma rays were first pressed between sheets of aluminum foil for a short time at elevated temperature to obtain a thin sheet, and then subjected to the vulcanization treatment. All the other samples were vulcanized under pressure in a Carver press.

Compounding was done on a laboratory rubber mill equipped with rolls $3 \mathrm{in.} \mathrm{by} 8$ in.

\section{Results}

The results of this study are presented in typical spectra given in figures 1 to 9 , which are discussed in detail along with related spectra, in the sections that follow. The arrows in the figures indicate the pertinent bands in this study. The results are summarized in table 1. This table indicates changes in bands and in band intensities as a result of the various vulcanization processes, and is included for convenient reference in reading the discussions.

In this table and in the following discussions, it is to be emphasized that conclusions involving changes in band intensities are to be viewed with caution. In general, the intensities of absorptions in films, in addition to thickness, are influenced by factors such as scatter, inhomogeneity, surface reflection, and the effect of neighboring bands. These factors are important in rubber and especially so when the added solids used in vulcanization are present.

Consequently, in a number of cases it was not possible to come to a definite decision regarding changes in band intensities. However, in cases where a change in intensity appeared to occur, the change has been noted as a possible or apparent change, with the intention of indicating to the reader that the intensity change is at least a possible result of the treatment discussed.

\subsection{Unvulcanized Natural Rubber}

Figure 1 shows the spectrum between 2 and $15 \mu$ of a film of natural rubber obtained by the evaporation of water from latex. This spectrum is essentially the same as that obtained by previous investigators. Sheppard and Sutherland [35] suggest that the band at $3.05 \mu$ may be due to the $\mathrm{C}-\mathrm{H}$ stretching vibration of the "lone" hydrogen on the ethylene bond in rubber. If, on the other hand, this band is due to $\mathrm{NH}$ groups in proteins perhaps, or to $\mathrm{OH}$ groups, its position indicates that these groups are strongly hydrogen bonded. No interpretation of the weak absorption near $4.9 \mu$ is possible beyond the fact that it occurs in the region where acetylenes, nitriles, isocyanates, allenes, and amino acids absorb; it is probably the same band that Sheppard and Sutherland [35] found at $4.98 \mu$. The bands near 5.75 and $5.85 \mu$ may indicate two types of carbonyls; they may be due to carbonyls already present in the hydrocarbon chain, or formed by oxidation of the chain, or else to carbonyls in the resinous portion. They are probably the small bands near $5.8 \mu$ mentioned by Dinsmore and Smith [12], and Saunders and Smith [30].

It is interesting to note that purification of natural rubber by the method of McPherson [26] does not change markedly the intensity of any of these bands. The purified rubber used here contained 98.7-percent rubber hydrocarbon, 0.44-percent protein, and 0.18percent ash. The sample also contained 1-percent phenyl-beta-naphthylamine added as an antioxidant, an amount that proved insufficient to affect the spectrum. This purified rubber had also been used by Roberts and Mandelkern [27] and was obtained from them. The fact that purification does not greatly reduce the intensity of these bands indicates that they are not related to the resin or protein content of the rubber, which is greatly reduced on

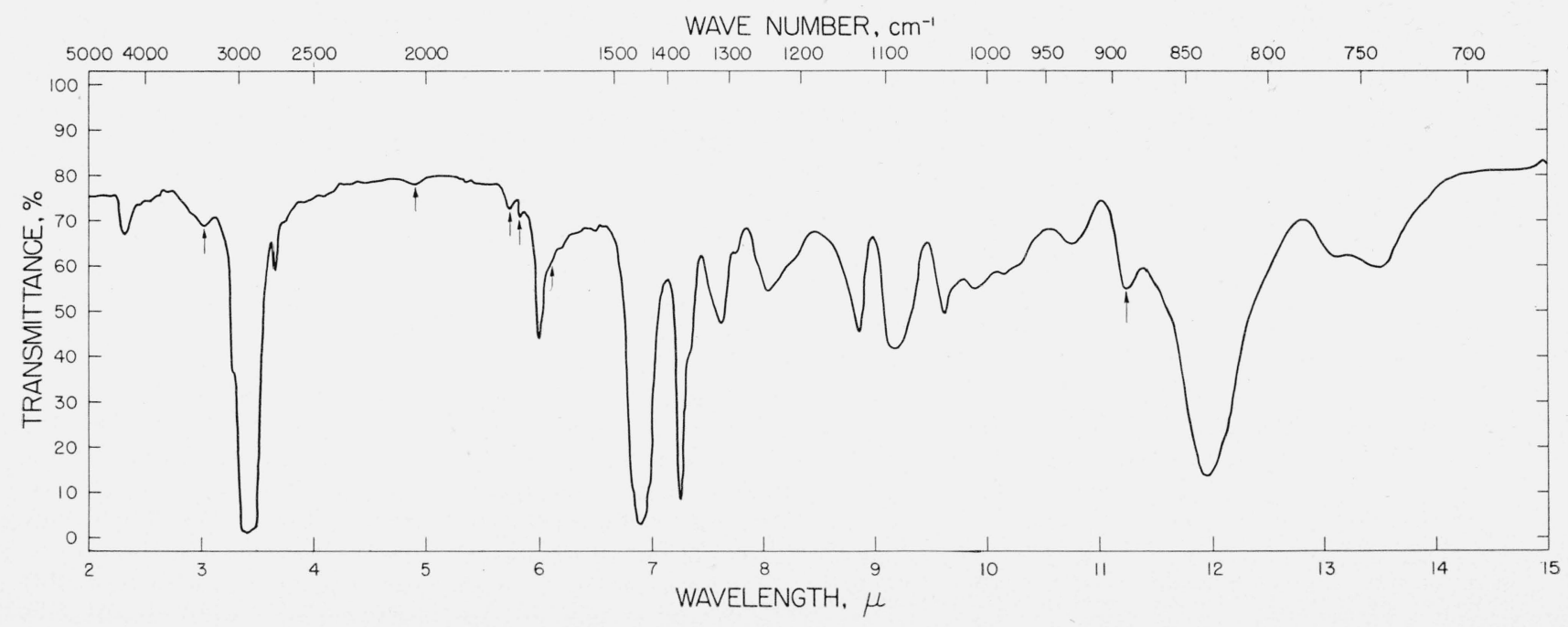

Figure 1. Infrared spectrum of film of dried natural rubber latex. 
TABLE 1. Spectral results and conclusions

P, Present; A, absent; I, increases; D, decreases; - , not investigated.

\begin{tabular}{|c|c|c|c|c|c|c|c|c|c|c|c|c|}
\hline \multirow{3}{*}{ Wavelength } & \multirow{3}{*}{$\begin{array}{l}\text { Previous } \\
\text { observa- } \\
\text { tions }{ }^{1}\end{array}$} & 1 & 2 & 3 & 4 & 5 & 6 & 7 & 8 & 9 & & \\
\hline & & \multicolumn{3}{|c|}{ Unvuleanized } & \multirow{2}{*}{$\begin{array}{l}\text { Sulfur } \\
\text { alone }\end{array}$} & \multirow{2}{*}{$\begin{array}{c}\text { Sulfur } \\
\text { and accel- } \\
\text { erators }\end{array}$} & \multirow{2}{*}{$\begin{array}{l}\text { TMTD } \\
\text { alone }\end{array}$} & \multirow{2}{*}{ Peachey } & \multirow{2}{*}{ Peroxide } & \multirow{2}{*}{$\underset{\text { rams }}{\operatorname{Gamma}}$} & \multirow{2}{*}{\multicolumn{2}{|c|}{ Remarks }} \\
\hline & & $\begin{array}{l}\text { Puri- } \\
\text { fied }\end{array}$ & $\begin{array}{l}\text { Dried } \\
\text { latex }\end{array}$ & $\begin{array}{l}\text { Coagu- } \\
\text { lated }\end{array}$ & & & & & & & & \\
\hline $\begin{array}{l}{ }_{2}^{\mu} .9 \\
3.05\end{array}$ & $\begin{array}{l}12,35 \\
12,30,35\end{array}$ & $\stackrel{\mathrm{A}}{\mathrm{P}}$ & $\stackrel{\mathrm{A}}{\mathrm{P}}$ & $\stackrel{\mathrm{A}}{\mathrm{P}}$ & $\stackrel{\mathrm{A}}{\mathrm{P}}$ & $\underset{\mathrm{I}}{\mathrm{A}}$ & $\stackrel{\mathrm{A}}{\mathrm{P}}$ & $\stackrel{A}{\mathrm{~A}}$ & $\stackrel{A}{\mathrm{~A}}$ & $\stackrel{\mathrm{A}}{\mathrm{I}}$ & $\begin{array}{l}\text { Probably oxidation band. } \\
\text { May be somewhat stronger in } 3 \text { than in } 1 \text { and } 2 \text {. May increase } \\
\text { in } 5 \text { with TMTD and } \mathrm{BZ} \text { and in } 7,8 \text {, and } 9 \text { (on } 9 \text {, see text). }\end{array}$ & Not markedly chang- \\
\hline $\begin{array}{l}\text { 4. } 90 \\
\text { 5. } 75\end{array}$ & $35^{2} \ldots \ldots$ & $\stackrel{\mathrm{P}}{\mathrm{P}}$ & $\stackrel{\mathrm{P}}{\mathrm{P}}$ & $\stackrel{\mathrm{P}}{\mathrm{P}}$ & $\stackrel{P}{P}$ & $\begin{array}{l}\mathrm{I} \\
\mathrm{D}\end{array}$ & $\stackrel{\mathrm{I}}{\mathrm{P}}$ & $\stackrel{\mathrm{P}}{\mathrm{D}}$ & $\stackrel{P}{D}$ & $\stackrel{\mathrm{P}}{\mathrm{D}}$ & $\begin{array}{l}\text { May increase in } 5 \text { with TMTD and in } 6 \text {. } \\
\text { Possible decrease in } 7,8,9 \text {, may be related to Either one or both }\end{array}$ & $\begin{array}{l}\text { fore, not wholly } \\
\text { characteristic of }\end{array}$ \\
\hline $\begin{array}{l}5.85 \\
6.02\end{array}$ & $\begin{array}{l}12,30^{3} \\
12,30,35\end{array}$ & $\stackrel{\mathrm{P}}{\mathrm{P}}$ & $\stackrel{\mathrm{P}}{\mathrm{P}}$ & $\stackrel{\mathrm{P}}{\mathrm{P}}$ & $\stackrel{P}{P}$ & $\underset{\mathrm{P}}{\mathrm{D}}$ & $\stackrel{\mathrm{D}}{\mathrm{P}}$ & $\stackrel{\mathrm{P}}{\mathrm{P}}$ & $\stackrel{\mathrm{P}}{\mathrm{P}}$ & $\stackrel{\mathrm{P}}{\mathrm{P}}$ & Possible decrease in 6 . & \\
\hline 6. $10\left\{\begin{array}{l}6.10 \\
6.13\end{array}\right.$ & None $4 \ldots$ & $\mathrm{P}$ & $P$ & $\mathrm{P}$ & $\mathrm{P}$ & $\mathrm{P}$ & $\mathrm{P}$ & $\mathrm{P}$ & $\mathrm{P}$ & $\mathrm{P}$ & $\begin{array}{l}\text { Band at } 6.02 \mu \text { unsymmetrical in purified rubber; inflection in } \\
\text { dried latex; shoulder in coagulated rubber; resolved at least } \\
\text { for sulfur vuleanizates; appears to become stronger relative to } \\
6.02-\mu \text { band in vulcanizates containing more than 12-percent } \\
\text { sulfur (see text). } \\
\text { Conjugated double bonds; band appears in sulfur vulcanizates }\end{array}$ & $\begin{array}{l}\text { These bands indicate } \\
\text { that considerable } \\
\text { unsaturation of } \\
\text { various types re- } \\
\text { mains even after } \\
\text { vulcanization with } \\
\text { 25-percent sulfur. }\end{array}$ \\
\hline 6.5 & $12,30,35$ & A & A & $\mathrm{P}$ & $\mathrm{P}$ & $\mathrm{P}$ & A & I & I & I & Present in 5 with smaller quantity of TMTD, otherwise presenc & ce in 5 and 6 may be \\
\hline 10.4 & $35,36 \ldots \ldots$ & A & A & A & $\mathrm{P}$ & $\mathrm{P}$ & A & A & A & $\mathrm{A}$ & Shifted double bond; confirmed for compounds containing more $t$ & than 2-percent sulfur; \\
\hline 11. 95 & $12,30,36 \ldots$ & $\mathrm{P}$ & $\mathrm{P}$ & $\mathrm{P}$ & D & D & $\mathrm{P}$ & $\mathrm{P}$ & $\mathrm{P}$ & $\mathrm{P}$ & Hydrogen on double bond in unvuleanized rubber. & \\
\hline $\begin{array}{l}14.3 \\
14.8\end{array}$ & None 4 & A & A & A & $\mathrm{P}$ & $\mathrm{P}$ & A & A & $A$ & A & $\begin{array}{l}\text { A ppear in sulfur vulcanizates containing more than 12-percent sulf } \\
\text { with accelerators ( } 15 \% \text { sulfur). }\end{array}$ & ur; sometimes present \\
\hline 14.5 & None ${ }^{4}$ & A & A & A & $\mathrm{P}$ & $\mathrm{P}$ & $\mathrm{P}$ & A & $A$ & A & Occurs in sulfur vulcanizates with less than 12-percent sulfur; usu: & ally present in $5(15 \%$ \\
\hline $\begin{array}{l}17.0 \\
17.5 \\
19.8\end{array}$ & $\begin{array}{l}35 \\
22,30,35 \\
22,30\end{array}$ & $\begin{array}{l}\mathrm{A} \\
\mathrm{P}\end{array}$ & $\stackrel{\mathrm{A}}{\mathrm{P}}$ & 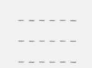 & $\begin{array}{l}\mathrm{P} \\
\mathrm{D} \\
\mathrm{D}\end{array}$ & 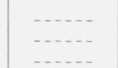 & -.... & -.... & ..... & 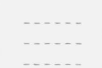 & $\begin{array}{l}\text { May be slight intensification of a shoulder on } 17.5-\mu \text { band in unvul } \\
\text { Band confirmed. } \\
\text { Band confirmed. }\end{array}$ & leanized rubber. \\
\hline $\begin{array}{l}23.5 \\
28.0\end{array}$ & None $4 . .$. & $\mathrm{P}$ & $\mathrm{P}$ & .... & A & -..... & ...... & -..... & -..... & ....... & Broad swellings centered near these wavelengths. & \\
\hline $\begin{array}{l}21.2 \\
22.7 \\
24.4 \\
26.6\end{array}$ & None 4 ... & A & A & & P & & & & & .... & These bands occur in region where $\mathrm{S}-\mathrm{S}$ linkages absorb. & \\
\hline
\end{tabular}

1 Numbers indicate references in literature cited.

2 Probably 4.98- $\mu$ band of reference 35 .
3 Probably one of weak bands near $5.8 \mu$ in reference 12 and 30.

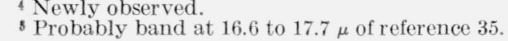




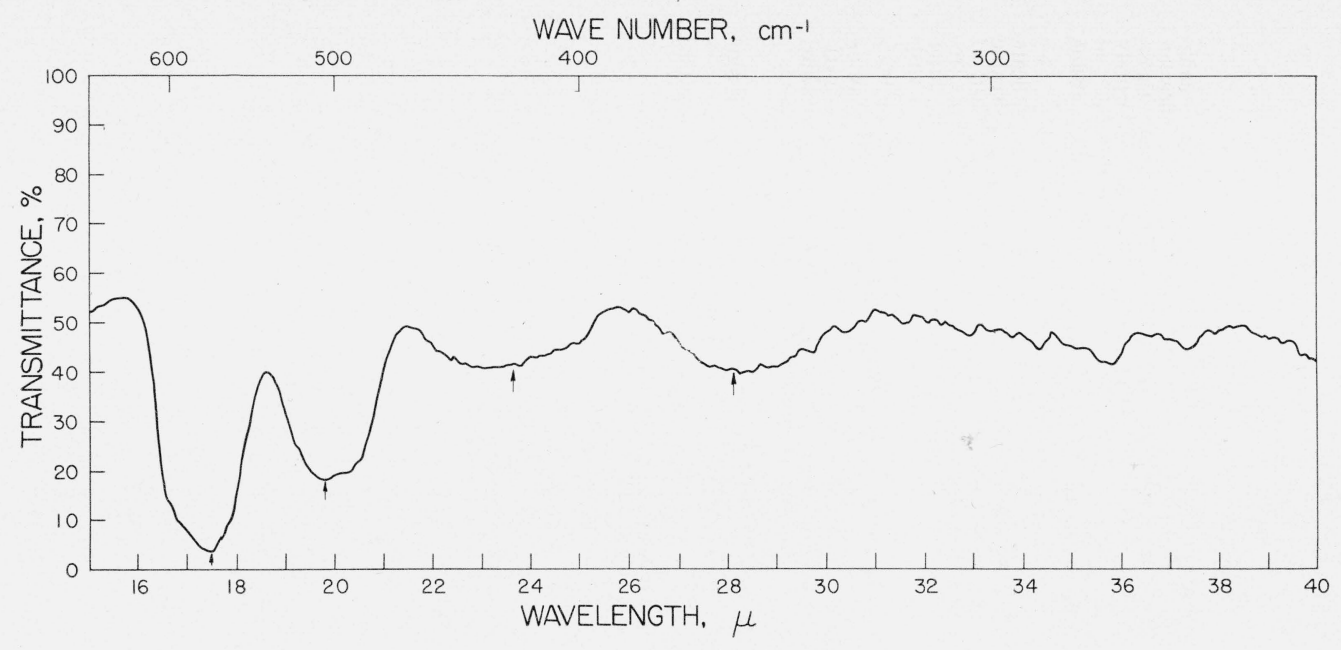

Figure 2. Far infrared spectrum of film of dried natural rubber latex.

purification, unless appreciable quantities of resinor proteinlike units are in some way part of the polymer chain. Dinsmore and Smith [12B], and Saunders and Smith [30], however, did not find the $3.05 \mu$ band in deproteinized rubber. It should be pointed out that it is possible to explain all four of these bands as either combinations or overtones of frequencies observed for absorptions in figures 1 and 2 . These bands are of interest here since their intensities may be affected by certain vulcanization processes.

There is an inflection point at $6.1 \mu$ in the spectrum of dried latex given in figure 1. This absorption is all but absent in the spectrum of purified rubber, the only evidence of its presence being the unsymmetrical nature of the band at $6.0 \mu$ which is broader on the longer wavelength side. On the other hand, this absorption appears as a strong shoulder in spectra of coagulated rubber, i. e., Tensocrepe, pale crepe No. 1 thin, pale crepe No. 1 thick, smoked sheet and Tensosheet. Dinsmore and Smith [12] first attributed this shoulder to absorption by a terminal double bond. In a later article Saunders and Smith [30] concluded that the band at $6.1 \mu$ was largely due to an impurity. The present work indicates that this impurity is probably introduced during coagulation. Apparently the strong shoulder at least is not, as suggested by Sheppard [34], an overtone of the $11.95 \mu$ band. It may be, however, that the residual absorption in purified rubber is due to terminal double bonds or to an overtone of the $11.95 \mu$ band. The slight difference between dried latex and purified rubber, if real, may be due to an impurity in dried latex.

The coagulated samples also showed what is probably a somewhat stronger absorption at 3.05 and a band at $6.5 \mu$. Again, these effects are apparently due to impurities introduced during coagulation and not removed by the washing process.

As a result of a comparison of spectra of smoked sheet and purified rubber, Saunders and Smith [30] seem to consider not only the band at 6.1 , but also the bands at $3.05,5.75,5.85$, and $6.5 \mu$ to be due largely to impurities.

Figure 2 shows the spectrum of dried natural rubber latex in the region between 15 and $40 \mu$. The spectrum of purified rubber is essentially the same. There are two broad absorptions with peaks near 17.5 and $19.8 \mu$, respectively, in reasonable agreement with the findings of other workers $[22,30]$. It is probably the former to which Sheppard and Sutherland [35] refer as extending from 16.6 to $17.7 \mu$. In addition, there are two very broad swellings between 21 and $30 \mu$ which have not been reported previously. The smaller bands beyond $30 \mu$ are due to uncompensated atmospheric water-vapor absorption.

\subsection{Vulcanization With Sulfur Alone}

In this work, some samples of natural rubber (pale crepe No. 1 thick) containing from 2- to 25-percent sulfur and no zinc oxide were vulcanized approximately to completion (about $20 \mathrm{hr}$ ) at $150^{\circ} \mathrm{C}$ while others containing 15-percent sulfur and no zinc oxide were vulcanized for periods of time ranging from 15 $\min$ to 4 days at $125^{\circ} \mathrm{C}$ and from $1 \mathrm{hr}$ to $20 \mathrm{hr}$ at $150^{\circ} \mathrm{C}$

Figure 3 gives the spectrum between 2 and $15 \mu$ of natural rubber vulcanized with 15 -percent sulfur for $96 \mathrm{hr}$ at $125^{\circ} \mathrm{C}$. In addition to the changes indicated in table 1, some other unexplained changes near $9.0 \mu$ have taken place during vulcanization. These changes become noticeable with about 5- to 8percent sulfur; they also occur in accelerated vulcanizates, but not in the other types of vulcanizates discussed here.

The band at $10.4 \mu$ not present in unvulcanized rubber has been interpreted by Sheppard and Sutherland [36] to be due to the out-of-plane de- 
formation vibration of the trans hydrogens on a double bond resulting from a shift of the following type:

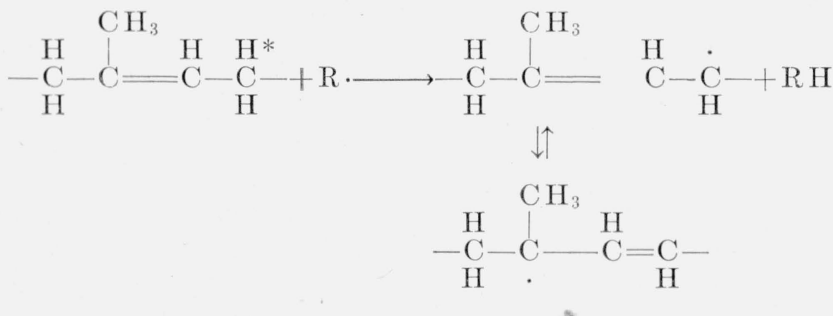

where $R$. is a free radical. These workers pointed out that this is consistent with the idea of $\alpha$-methylenic initiation of the sulfuration reaction as advanced by Farmer and Shipley [16]. Sheppard and Sutherland found the intensity of this band to be correlated with the amount of combined sulfur. In this case the attack took place on the $\alpha$-methylene group marked with an asterisk. This change in the spectrum would, of course, not occur if the attack had taken place on the $\alpha$-methylene group on the other side of the double bond. In the present work, this band was observed in fully vulcanized compounds containing only 2percent sulfur, the smallest quantity studied here, and it increased in intensity and shifted to slightly longer wavelengths (ca. 10.35 to $10.44 \mu$ ) as the sulfur content was increased from 2 percent to 25 percent. It will be referred to, however, as the band at $10.4 \mu$. As would be expected, the intensity of the band at $11.95 \mu$ related to the hydrogen on the original double bond decreased with an increase in the intensity of the band at $10.4 \mu$.

The weak absorptions at 14.3 and $14.8 \mu$ could be due to the hydrogens on the corresponding cis configuration. It is reasonable to expect both isomers to be formed during the double-bond shift. These bands could also be caused, however, by $\mathrm{C}$ - S linkages, or by skeletal vibrations not characteristic of any particular functional group. These bands appear as separate absorptions in fully vulcanized compounds containing more than 12-percent sulfur. With sulfur concentrations from 2 to 12 percent, only a broad general absorption appears that is centered near $14.5 \mu$. The newly discovered sharp band at $6.25 \mu$ occurs in the region where conjugated double bonds absorb, and is treated separately in a later section. It occurs in all rubber-sulfur vulcanizates containing 5 percent or more of sulfur, and its intensity increases with increasing sulfur content.

The weak broad band near $6.5 \mu$ is presumably the same band reported by Sheppard and Sutherland [35] as occurring at $6.52 \mu$ in unvulcanized rubber mixes to which stearic acid and zinc oxide had been added. They attributed this band to the stearate ion and reported that it disappeared on vulcanization. However, Ellis and Pyszora [13] have shown that the intensity of the band increases again to approximately its original value when the specimen is allowed to remain at room temperature for $18 \mathrm{hr}$. They attribute the observed effects to an interaction between natural rubber and zinc sterate that is not related to the vulcanization process. The compound used to obtain figure 3 did not contain arded zinc oxide or stearic acid, but the original rubber sample showed an absorption at $6.5 \mu$ which, as suggested earlier, may result from impurities introduced during coagulation. The intensity of this band sometimes appeared to be reduced on vulcanization in this work.

The presence of zine oxide in sulfur vulcanizates of Tensocrepe or pale crepe No. 1 thin, leads to no apparent change in the rate of the double-bond shift and the band at $6.25 \mu$ appears about as soon as it does without zinc oxide. There usually seems to be some reduction in the intensity of either or both the carbonyl bands near 5.75 and $5.85 \mu$.

There is a change in the relative intensities of the bands at 6.0 and $6.1 \mu$ as a result of vulcanization. The increase of the $6.1-\mu$ band relative to the band at $6.0 \mu$ is noticeable in compounds containing

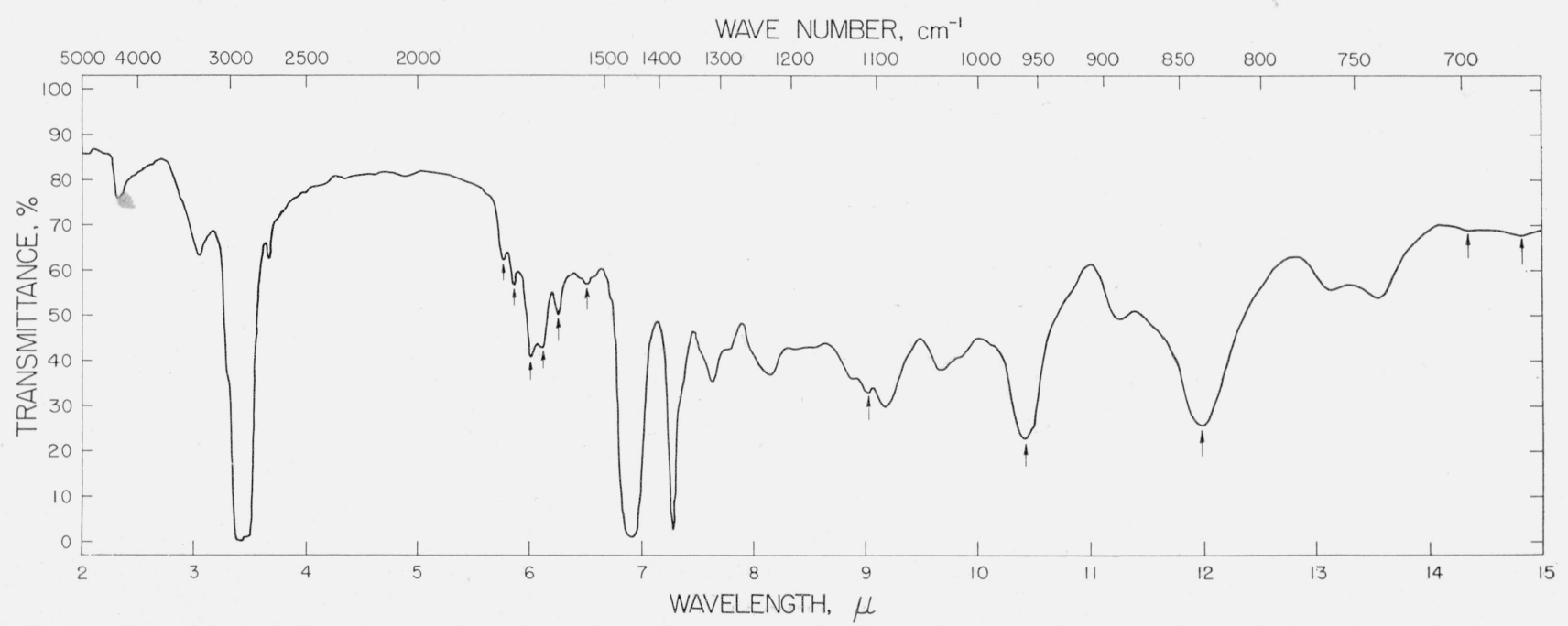

Figure 3. Infrared spectrum of natural rubber (pale crepe No. 1 thick) vulcanized with 15 -percent sulfur for 96 hr at $125^{\circ}$ C. 
12-percent sulfur, and increases with increased sulfur content until with 25-percent sulfur it becomes the more prominent band, while the band at $6.0 \mu$ appears only as a shoulder.

Under higher resolution, the band at $6.1 \mu$ in vulcanized rubber may be resolved into two components at 6.10 and $6.13 \mu$ with the main " $6-\mu$ " band appearing at $6.02 \mu$. The shoulder at $6.1 \mu$ in unvulcanized rubber could also be due to two components, but this fact is not quite as apparent as in the case of vulcanized rubber.

At present it cannot be said with certainty whether there is an actual increase in the intensity of the $6.1-\mu$ band on vulcanization or whether the observed relative change is due entirely to a decrease in the $6.0-\mu$ band.

Because of the uncertainty of the nature of the band at $6.1 \mu$, and because the absorptivity of double-bond stretching vibrations is quite variable, no quantitative statement can be made about changes in unsaturation during vulcanization except that in accordance with the results of previous workers $[28,35,36]$ even with 25-percent sulfur considerable unsaturation of various types including those absorbing at $6.1 \mu$ remains. To this residual unsaturation should now be added that due to the conjugated double bonds absorbing at $6.25 \mu$.

The same structural changes take place when natural rubber is vulcanized at $150^{\circ} \mathrm{C}$ but at an accelerated rate. There is often some increase in carbonyl structure, which also results from heating rubber alone at this temperature.

It is interesting to note that in a spectrum of a vulcanizate of Coral rubber, a syn thetic polyisoprene [37], the intensities of the band at $6.25 \mu$ indicating conjugation and the band near $6.1 \mu$ were considerably greater relative to the band at $6.0 \mu$ than in the case of vulcanized natural rubber with the same amount of added sulfur $(15 \%)$. The band at $6.0 \mu$ was reduced to a slight shoulder on the band at $6.1 \mathrm{\mu}$. The spectrum of the unvulcanized Coral rubber used here contained small bands near 6.1, $6.2,6.3$, and $6.65 \mu$.

Figure 4 shows the spectrum between 15 and $40 \mu$ of natural rubber (pale crepe No. 1 thick) vulcanized with 13 -percent sulfur for $20 \mathrm{hr}$ at $150^{\circ} \mathrm{C}$. It will be noted that: (1) There is some reduction in the intensity of the band at $17.5 \mu,(2)$ the broad band at $19.8 \mu$ is reduced, (3) the two consecutive swellings in the region between 21 and $30 \mu$ have disappeared, and (4) these swellings have been replaced by weak bands at $21.2,22.7,24.4$, and $26.6 \mu$. No interpretation of these bands is possible at the present time beyond the observation that $\mathrm{S}-\mathrm{S}$ linkages absorb in this region.

The band at $17.0 \mu$, mentioned by Sheppard and Sutherland [35] appears possibly as a slight intensification of a shoulder on the original band at $17.5 \mu$.

Gehman [19], and Gehman and Osterhoff [20] have obtained Raman spectra of portions of acetoneextracted rubber soluble in petroleum ether or ethyl ether. Apparently, reported attempts to obtain Raman spectra of whole rubber have been unsuccessful because of difficulties due to Rayleigh scattering by rubber and by particles in the rubber as well as fluorescence of the nonrubber constituents of the whole sample. Attempts at the Bureau to obtain Raman spectra of whole rubber both unvulcanized and vulcanized have also been unsuccessful for the same reason. Raman spectra of vulcanized rubber, if obtained, would shed light on the existence of $\mathrm{C}-\mathrm{S}$ and $\mathrm{S}-\mathrm{S}$ linkages, which are generally known to produce stronger effects in the Raman spectrum than in the infrared, and should aid in establishing the identity of some of the infrared bands observed in this work.

\subsection{Reaction Between Squalene and Sulfur}

Squalene (a hexaisoprene), having a lower molecular weight and being a liquid, is more useful for certain experiments than rubber. It has been suggested

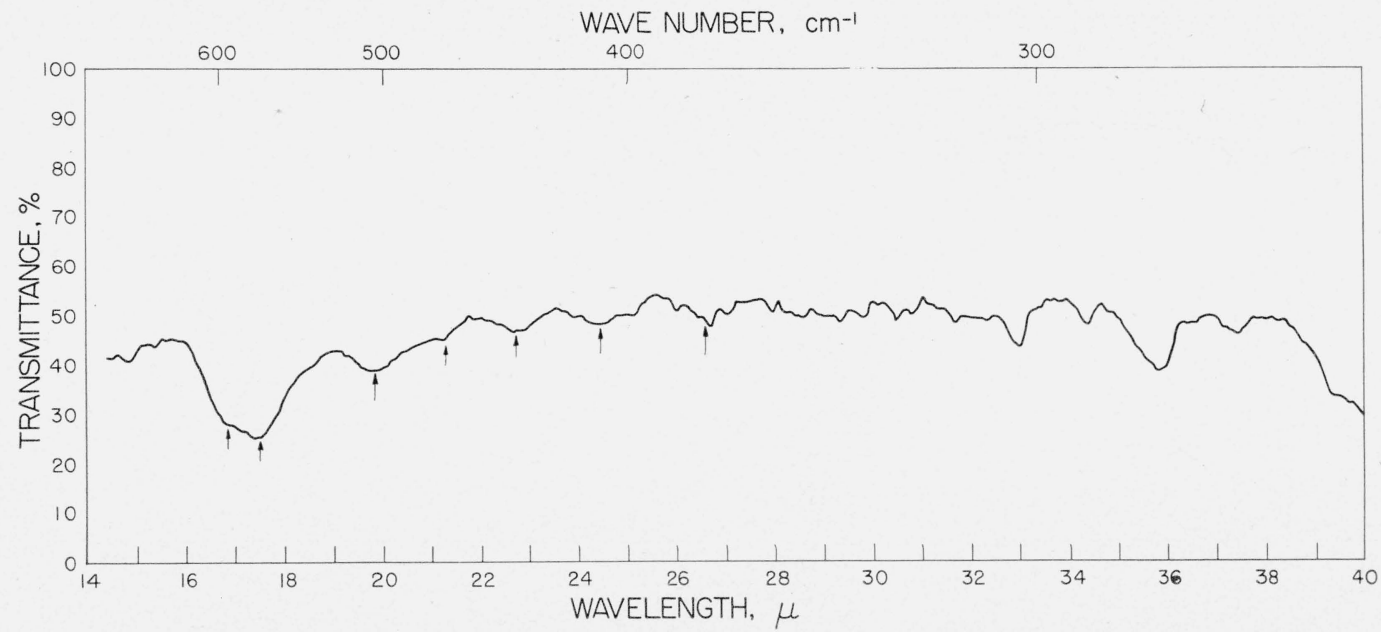

FIGURE 4. Far infrared spectrum of natural rubber (pale crepe No. 1 thick) vulcanized with 13 -percent sulfur for 20 hr at $150^{\circ}$ C. 
by Bloomfield [5] that squalene, because of its molecular complexity, is more similar to long chain polyisoprenes than smaller compounds that have been used as rubber substitutes. It should be well adapted for the study of the structural changes of the double-bond shift and conjugation discussed here. If we consider two adjacent isoprene units in the squalene molecule

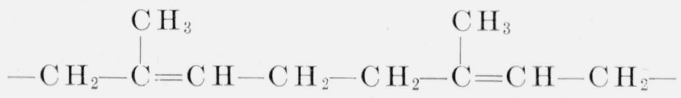

it will be seen that a conjugated system could appear as a result of either a shift of two double bonds toward each other or two successive shifts of one double bond. It could also result from the introduction of a new double bond between two original double bonds. Similar possibilities for conjugation of this type, of course, exist in natural rubber. The spectrum of Eastman practical grade $(90 \%)$ squalene given in the upper part of figure 5 is essentially the same as that obtained by other workers $[9,10,11,38]$. It is similar in many respects to that of rubber as shown in figure 1, including the band at $6.0 \mu$ and the strong absorption at $12.0 \mu$, probably due to the hydrogen on the carbon adjacent to the double bond. Furthermore, it has no absorption at $10.4 \mu$ characteristic of trans hydrogens adjacent to a double bond, and there is no band at $6.25 \mu$ indicating conjugation.

This material was reacted for $221 / 2 \mathrm{hr}$ at $150^{\circ} \mathrm{C}$ with sulfur in a sealed tube under nitrogen. The squalene-sulfur reaction product was very dark and more viscous than the original squalene. The spectrum of the reaction product is given in the lower part of figure 5. This spectrum contains the bands at 10.4 and $6.25 \mu$. The new band near $6.1 \mu$ is accompanied in this case by an increase in the absorption at $11.25 \mu$. Both effects have been $[12 \mathrm{~A}, 29]$ related to the formation of terminal double bonds. This situation is different from that observed with rubber vulcanizates for which an increased absorption at $11.25 \mu$ was not observed (figs. 1 and 3 ). The migration of double bonds in squalene as a result of different treatments has been discussed by other authors $[9,11]$. In their study of double bond migrations in squalene during hydrogenation and dehydrogenation, Dale and Artun [9] found evidence of conjugation in the ultraviolet spectrum but no band at $6.25 \mu$ in the infrared spectrum. There are also two bands near 14.5 and $14.9 \mu$ which are reasonably close to the bands at 14.3 and $14.8 \mu$ which in sulfur vulcanizates were attributed to the $\mathrm{C}-\mathrm{S}$ linkage, to hydrogens cis to a double bond, or to skeletal vibrations.

\subsection{Chemical Evidence of Conjugated Double Bonds}

Farmer and Shipley [16] have discussed the possibility of conjugated systems in vulcanization. Other authors $[2,4,6,15]$ have mentioned apparently conjugated reaction products formed in the study of vulcanization using small molecules.

The band observed in these studies at $6.25 \mu$, if not due to conjugation, could be the result of combinations or overtones of absorptions occuring at other frequencies. None of the bands or combinations of bands observed to increase on vulcanization could account for the $6.25-\mu$ band in this manner. However, in view of the apparent importance of this band, which is discussed later, it was deemed desirable to attempt to verify the presence of conjugated systems by chemical means.

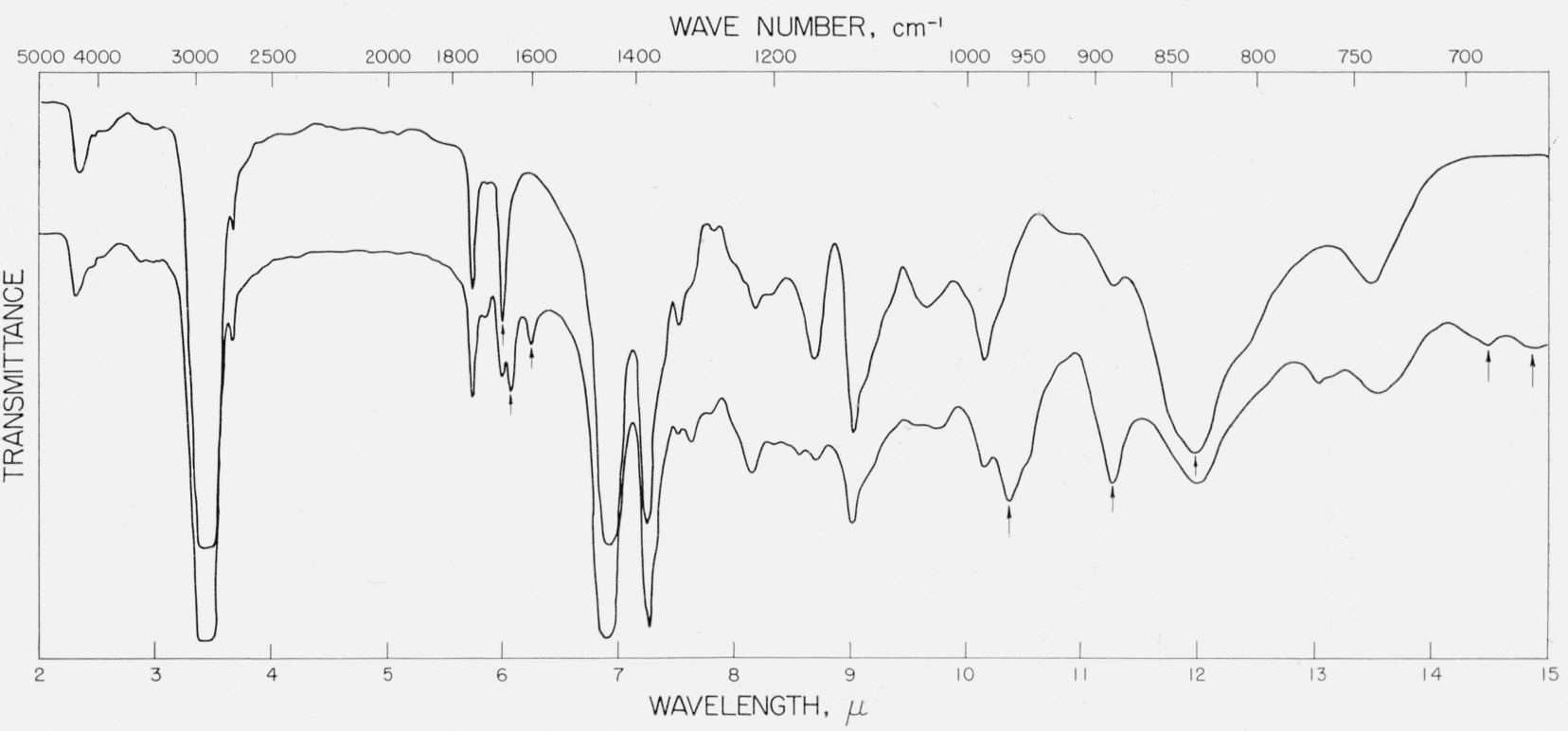

FIGURE 5. Infrared spectra of squalene and squalene-sulfur reaction product. 
This was accomplished by demonstrating that a reaction takes place between the squalene-sulfur reaction product and maleic anhydride and that, as a result of this reaction, the band at $6.25 \mu$ is removed.

Compounds containing conjugated double bonds normally react with maleic anhydride to form adducts in which the conjugation is removed not only from the compound in question but also from the anhydride. Examples of this Diels-Adler type of reaction are described by Kloetzel [24].

A portion of the squalene-sulfur reaction product $(0.17 \mathrm{~g})$ was mixed with $0.04 \mathrm{~g}$ of maleic anhydride, Fisher reagent. The mixture was agitated and heated for about 15 min to produce good mixing and a spectrum was obtained using a heated cell to keep the mixture molten. This spectrum is given in the upper half of figure 6. Absorptions near $5.05,5.2,5.4,5.6,7.8,7.9,8.1,9.5,11.25,11.55$, 11.9 , and 14.35 are at least in part due to the presence of maleic anhydride. It will also be noted that the bands near 6.0 and 6.1 due to the squalenesulfur reaction product are quite apparent. The broadening of the band at $6.25 \mu$ is probably due to the absorption of the maleic anhydride that occurs at $6.27 \mu$. Though there is no evidence of complete removal of conjugation, the extension of the band at $10.4 \mu$ to $10.55 \mu$ indicates that some reaction has already taken place.

This mixture was then reacted for $70 \mathrm{hr}$ at $100^{\circ} \mathrm{C}$ in a sealed tube under nitrogen. The tube was cooled, broken open, and the reaction mixture heated until completely melted. After mixing with a spatula, a spectrum was obtained in a heated cell to maintain the liquid state of the sample.
The spectrum of the final reaction mixture is given in the lower part of figure 6 . Increased absorption near $5.8 \mu$ and just beyond 8.0 and $9.0 \mu$ as well as the greatly increased absorption from about 10.5 to beyond $11.0 \mu$ indicate that reaction has taken place. The continued absorption at 6.0 and $6.1 \mu$ indicates that at least a portion of this part of the squalene-sulfur reaction product is still intact. It will be noticed that the band at $6.25 \mu$ has been removed completely, leaving, in fact, a slightly increased transmittance. The fact that a reaction has taken place and the band at $6.25 \mu$ has been removed is evidence of the presence of conjugated double bonds in the original reaction product. It is interesting to note that there is still absorption at $10.4 \mu$ probably due in part, at least, to shifted double bonds which are not conjugated. This, of course, assumes that the double bond in the final reaction product is cis as in the case of the reaction product obtained with butadiene and maleic anhydride [17, 24].

A sample of unreacted squalene mixed with maleic anhydride and run as a control showed no change after heating, except for the production of a band at $10.9 \mu$ and shoulders at 5.35 and $5.85 \mu$ indicating that the other changes observed with the squalene-sulfur reaction product are probably due to the Diels-Adler type of reaction. The quantity of maleic anhydride used in the above experiment was sufficient to react completely with one conjugated system per squalene molecule. Doubling this quantity of anhydride led to the same spectral picture, but increasing it fivefold obscured all the bands of the squalene-sulfur reaction product.

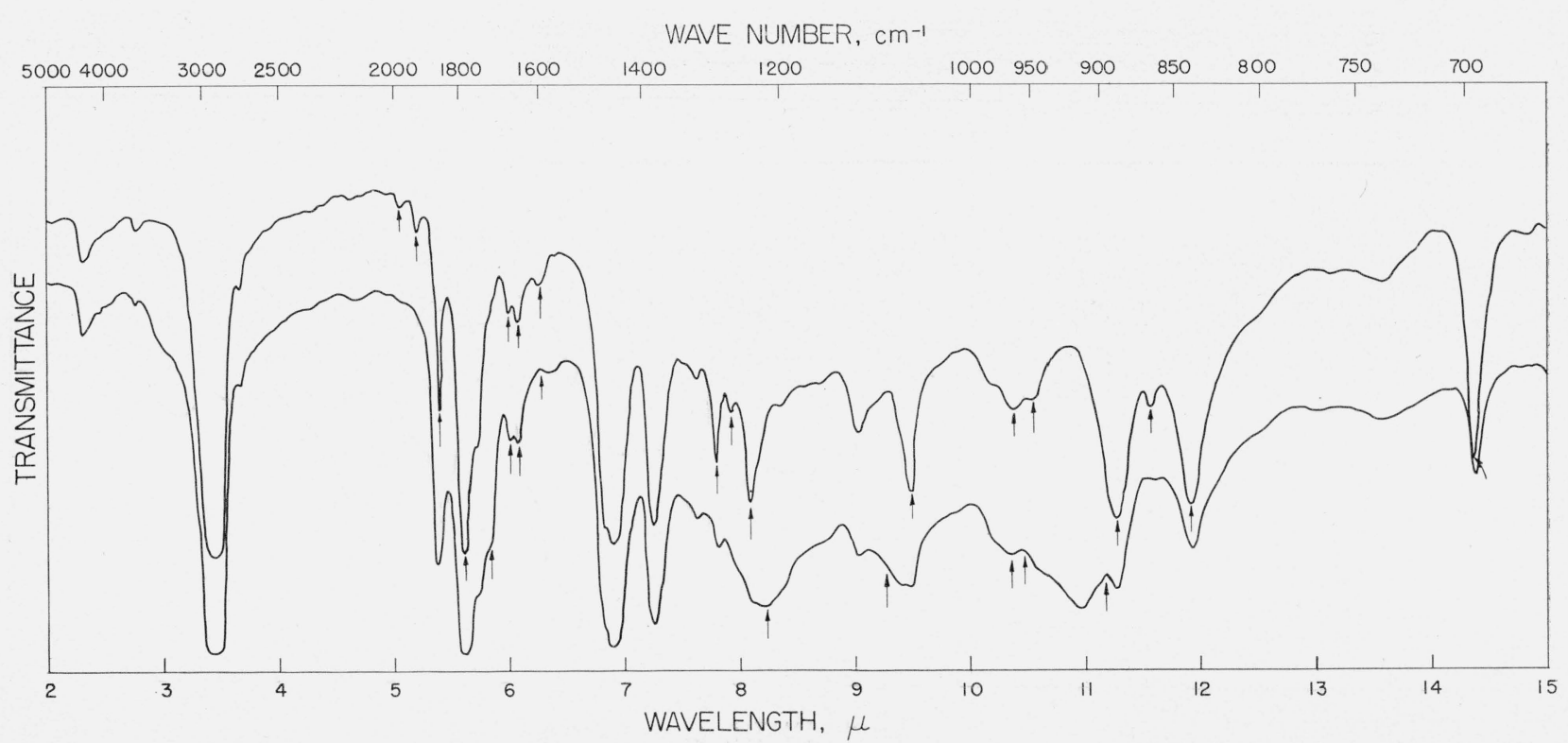

FiguRE 6. Infrared spectra of squalene-sulfur reaction product and maleic anhydride.

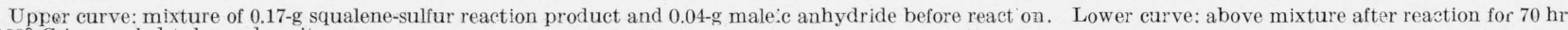
at $100^{\circ} \mathrm{C}$ in a sealed tube under nitrogen. 
Preliminary work had shown that the reaction between maleic anhydride and the squalene-sulfur reaction product does not take place in 8 days at room temperature. Backer and Blaas [1] have used temperatures between $150^{\circ}$ and $165^{\circ} \mathrm{C}$ in reactions involving thioether compounds containing conjugated double bonds, molecular types which might be present in the squalene-sulfur reaction product. These higher temperatures were avoided here in an attempt to eliminate the non-Diels-Adler type reactions involving maleic anhydride and various hydrocarbons [17].

It is interesting to note that, since maleic anhydride does not react with the benzene nucleus, the conjugated systems in the squalene-sulfur reaction product are not phenyl rings. This conclusion is consistent with the spectrum in the lower half of figure 5 which shows no change in the 11 - to $15-\mu$ region where various aromatic compounds absorb. Similarly, this lack of new bands in the $11-$ to $15-\mu$ range in the spectrum of vulcanized rubber indicates that the conjugation in vulcanized rubber is probably not caused by phenyl rings which might result from reversion during the vulcanization process.

Using purified squalene available only in small quantities, spectra were obtained on squalene and the squalene-sulfur reaction product in order to determine the effect of the impurities present in the practical grade. Except for the absence of carbonyl groups in the purified material, the spectra of the unreacted and reacted samples were qualitatively similar. Reaction of maleic anhydride with squalene-sulfur reaction product obtained from purified squalene also resulted in removal of the band at $6.25 \mu$. There was, however, a sharper band at $5.8 \mu$, and differences in the absorption pattern between 9 and $11 \mu$. These differences are not unexpected in view of the purified nature of the sample.

Following the work with squalene, attempts were made to remove the band at $6.25 \mu$ in rubber-suliur vulcanizates by adding various dienophiles to the compound before vulcanization. Of the reagents tried, maleic anhydride, diethyl fumarate, di $(2-$ ethylhexyl) maleate and dicetyl maleate, only diethyl fumarate produced an apparent decrease in the intensity of the band at $6.25 \mu$. The larger quantity $(13.5 \%)$ produced a greater apparent effect than the smaller quantity $(5 \%)$, but did not completely remove the band.

TABLE 2. Accelerated compounds

\begin{tabular}{|c|c|c|c|c|c|c|}
\hline \multirow{2}{*}{ Constituent } & \multicolumn{6}{|c|}{ Amount in compound } \\
\hline & A & B & $\mathrm{C}$ & D & $\mathrm{E}$ & $\mathrm{F}$ \\
\hline $\begin{array}{l}\text { Pale crepe No. } 1 \text { thin } \\
\text { Tensscrepe } \\
\text { Sulfur- } \\
\text { Tetramethylthiuram disulfide } \\
\text { (TMTD) } \\
\text { Zinc dibutyl dithiccarbamate } \\
\text { (BZ) } \\
\text { Mercaptsbenzothiazole (MBT) } \\
\text { Zine oxide. }\end{array}$ & $\begin{array}{c}\% \\
83 \\
15 \\
1.5 \\
- \\
0.5\end{array}$ & $\begin{array}{c}\% \\
77^{\circ} \\
15 \\
7.5 \\
- \\
0.5\end{array}$ & $\begin{array}{l}\% \\
77^{\circ} \\
15 \\
- \\
7.5 \\
0.5\end{array}$ & $\begin{array}{l}\% \\
77.5 \\
15 \\
7.5 \\
\ldots \\
-. \\
-\end{array}$ & $\begin{array}{l}\% \\
77.5 \\
15 \\
- \\
7.5 \\
--\end{array}$ & $\begin{array}{l}\% \\
77 \\
15\end{array}$ \\
\hline
\end{tabular}

\subsection{Vulcanization With Sulfur and Accelerators}

In order to determine the effect of accelerators on some of the structures found in unaccelerated samples, spectra were obtained on the vulcanizates of pale crepe rubber given in table 2 . The quantities of sulfur and accelerator used in these studies were much larger than those used in conventional compounds in order to produce pronounced effects in the infrared spectra. Compounds A through E were vulcanized at $125^{\circ} \mathrm{C}$ for periods of time up to $48 \mathrm{hr}$. Compound $\mathrm{F}$ was vulcanized for from $7 \frac{1 / 2}{2}$ min to $8 \mathrm{hr}$ at $150^{\circ} \mathrm{C}$.

In samples accelerated with TMTD and BZ (compounds $A$ through $\mathrm{E}$ ) the rate of the doublebond shift was greater than in the unaccelerated samples. For example, about as much double-bond shift occurred in $2 \mathrm{hr}$ in samples accelerated with BZ as occurred in $16 \mathrm{hr}$ with samples accelerated with the larger quantity of TMTD. This same amount of double-bond shift occurs in about 48 to $70 \mathrm{hr}$ in unaccelerated samples. The effect of the smaller quantity of TMTD on the double-bond shift may not have been as great as that of the larger quantity.

In comparison with unaccelerated compounds, however, conjugation, as determined by the presence of a band at $6.25 \mu$, was either virtually eliminated or its first appearance was delayed relative to a given amount of double-bond shift. Moreover, once slight conjugation had appeared, further vulcanization of these accelerated compounds did not cause as great an increase in the amount of conjugation as was observed in unaccelerated compounds.

In all cases the relative change in the intensities of the bands at 6.0 and $6.1 \mu$ was observed as was in all but the shorter cures, a band or bands between 14 and $15 \mu$. The band at $6.5 \mu$ was present in samples containing the smaller quantity of TMTD only; in the other samples it was probably partly obscured by bands from. TMTD and BZ.

In samples accelerated witb mercaptobenzothiazole (MBT) the rate of the double-bond shift was again more rapid than without the accelerator but nothing could be determined regarding the presence of conjugation since the benzene nucleus in the accelerator also has an absorption at $6.25 \mu$.

In some of the samples accelerated with TMTD and BZ, there may be an intensification of the band at $3.05 \mu$. There may also be an increase in the intensity of the small band at $4.9 \mu$ in a few of the samples accelerated with TMTD. Accelerators also seem to reduce either or both of the carbonyl bands near 5.75 and $5.85 \mu$.

\subsection{Vulcanization With TMTD}

Compounds of pale crepe No. 1 thin containing 15-percent TMTD and 0.5 -percent $\mathrm{ZnO}$ alone were vulcanized at $125^{\circ}$ and $150^{\circ} \mathrm{C}$ for periods of time varying from. $7 \frac{1}{2} \mathrm{~min}$ to $40 \mathrm{hr}$ at the lower and $8 \mathrm{hr}$ at the higher temperature. A spectrum of a sample 
vulcanized for $2 \mathrm{hr}$ at $125^{\circ} \mathrm{C}$ is typical and is given in figure 7. Unlike spectra of compounds in which TMTD serves as an accelerator in sulfur vulcanization, this spectrum shows no evidence of either conjugation or the double-bond shift indicated by bands at 6.25 and $10.4 \mu$, respectively. There is, however, an absorption near $10.3 \mu$. There also seems to be no appreciable change in the absorptions at 12.0 and near $6 \mu$ as a result of different periods of vulcanization, indicating that the double bond in the polymer is not noticeaoly affected.

After curing there is sometimes an apparent in crease in the intensity of the weak band observed at $4.9 \mu$. As curing proceeds, there is a decrease in absorptions at $6.65,8.1,8.7,9.6$, and $10.3 \mu$, wavelengths at which TMTD itself absorbs. This indicates destruction of the TMTD during the curing process. The band at 5.85 attributed to carbonyl absorption in rubber seems to be reduced. The band at $14.5 \mu$ appears in samples vulcanized over $4 \mathrm{hr}$. Again, the band at $6.5 \mu$ may be obscured by a band in TMTD.

In some samples vulcanized for the longer periods of time, there is increased absorption near $10.4 \mu$ which disappears after the sample has been allowed to stand in air at room temperature.

\subsection{Vulcanization by the Peachey Process}

In preparing samples for this type of vulcanization, one piece of aluminum was stripped off the pressed sample leaving the rubber film on the other piece of aluminum. The rubber film (pale crepe) on the aluminum was cut into small strips and these strips were attached to a wire rack in a tube and vulcanized by the Peachey process for from 1 to 24 cycles as described in the paper by Bekkedahl, Quinn, and Zimmerman [3]. A single cycle consisted of passing sulfur dioxide over the sample for 5 min, followed by a brisk 10 -sec sweep of air to remove the sulfur dioxide gas not absorbed by the samples, and then passing hydrogen sulfide over the sample for $5 \mathrm{~min}$, followed by another brisk 10-sec sweep of air.

Spectra were obtained on a number of these samples, of which the one given in figure 8 for the sample receiving an 8 -cycle treatment is typical. It will be noted that there is no evidence of the double-bond shift, of conjugation or of bands between 14 and $15 \mu$. There is also little evidence of changes in absorption at 12.0 and near $6 \mu$.

The absorption at $3.05 \mu$ appears stronger. The carbonyl absorption at $5.75 \mu$ appears to be reduced, and the strong absorption at 6.5 due to ionized carboxyl or to nitro groups may be intensified. If the $6.5-\mu$ band is actually due to ionized carboxyl groups, it would appear that the band at $5.75 \mu$ is related to the carboxylic acids in the rubber. Since the band at $5.75 \mu$ is not greatly affected by purification, some of these acids may be attached to the polymer chain. In addition, there are some slight changes in absorption near $9.8 \mu$.

The intensities of these various bands do not seem to change much from 2 to 24 cycles. For the more highly vulcanized samples there seemed to be a tendency for the other carbonyl absorption at $5.84 \mu$ to be reduced. At 24 cycles there was some slight evidence of a band at $10.4 \mu$. However, the more highly vulcanized samples had thickened during the process and comparison of their spectra with others was rather difficult. It should be noted that only two cycles are required for an optimum cure and that a sample treated with 24 cycles might be expected to contain nearly 9.0 percent combined sulfur, while one treated with only 8 cycles might contain somewhat over 7 percent combined sulfur [3].

Salomon and Van der Schee [28] observed no changes in the infrared spectrum of rubber vulcanized by the Peachey process.

It is interesting to note that, while an active sulfur radical has been assumed to produce the doublebond shift in sulfur vulcanization [18], no double-

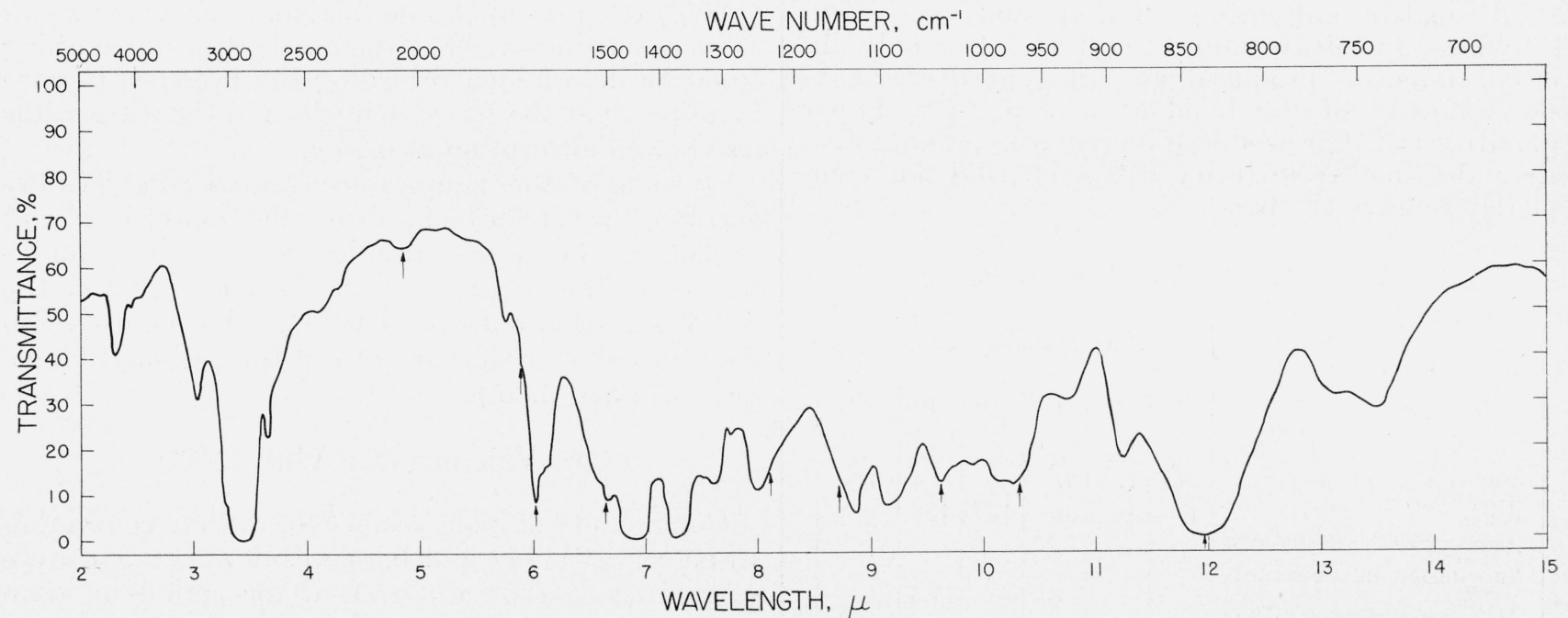

FIGURE 7. Infrared spectrum of natural rubber (pale crepe No. 1 thin vulcanized with 15-percent tetramsthylthiuram disulfide (TMTD) and 0.5-percent zinc oxide for $2 \mathrm{hr}$ at $125^{\circ} \mathrm{C}$. 


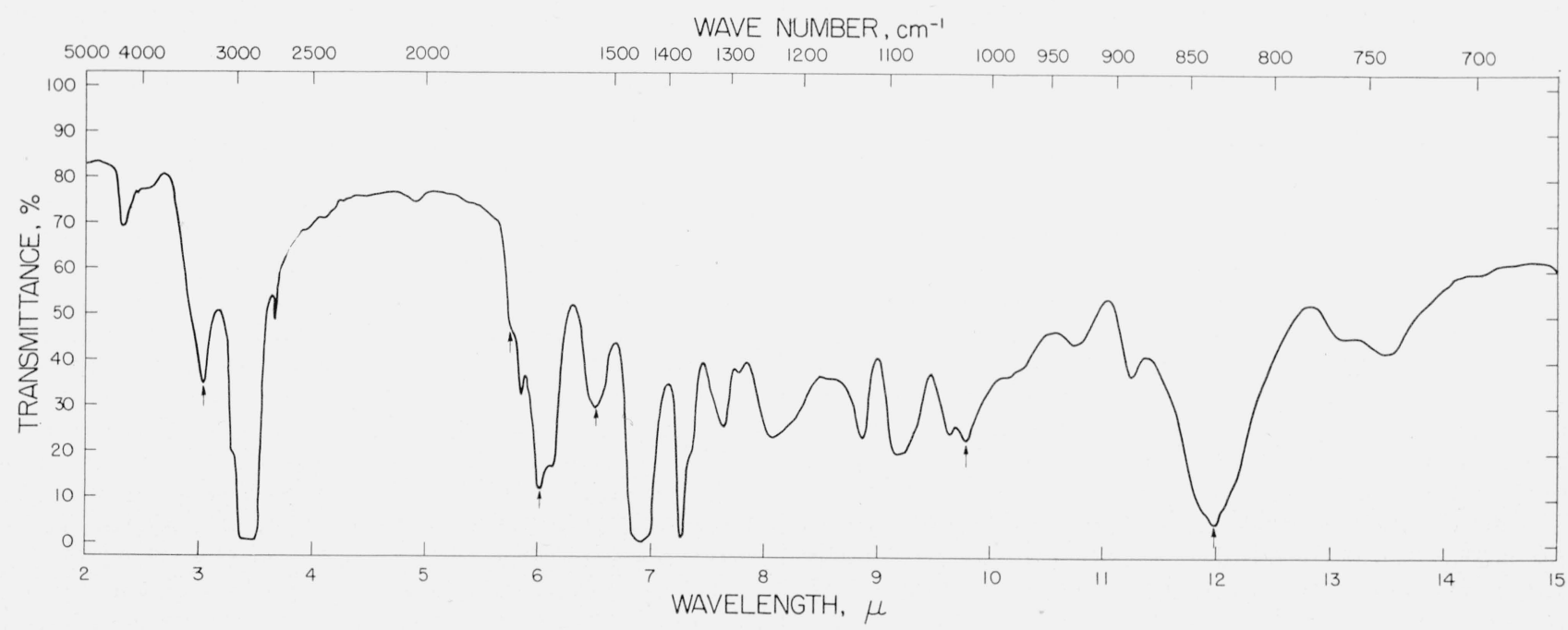

FIGURE 8. Infrared spectrum of natural rubber (pale crepe) vulcanized with sulfur dioxide and hydrogen sulfide (Peachey process) using $\delta$ cycles of both gases.

bond shift occurs in the Peachey process which is also believed to involve an active form of sulfur [23].

\subsection{Vulcanization With Di-Tertiary Butyl Peroxide}

In comparing peroxide vulcanization with sulfur vulcanization it was necessary to choose a peroxide that did not contain conjugated double bonds. Ditertiary butyl peroxide was satisfactory from this standpoint and has received some study $[7,14]$. It is believed to act by a free radical mechanism, does not combine with the polymer, and forms only volatile decomposition products, tertiary-butanol and acetone [14]. Furthermore, the oxygen content of the vulcanizate is said to be not significantly higher than that of the raw rubber [14].

Samples of pale crepe natural rubber were prepared containing 1.5-, 4.0-, and 7.25-percent peroxide. These samples were vulcanized for different periods of time varying from $15 \mathrm{~min}$ to $24 \mathrm{hr}$ at $125^{\circ}$ and $135^{\circ} \mathrm{C}$. The spectrum given in figure 9 was typical and was obtained on a sample containing 4.0-percent peroxide vulcanized for $2 \frac{1}{2} \mathrm{hr}$ at $135^{\circ} \mathrm{C}$. The apparent changes have been noted in Peachey vulcanization. There is a possible increase in the intensities of the bands at 3.05 and $6.5 \mu$, and a possible reduction in the carbonyl absorption at $5.75 \mu$.

It was found, however, that these apparent changes were present in a sample (containing $7.25 \%$ peroxide) which had not been vulcanized, i. e., heated above the temperature involved in milling. However, this sample exhibited none of the mechanical properties of the vulcanized materials, nor was it transparent and free from tackiness. Different times of vulcanization for the samples containing the different quantities of peroxide did not change the spectrum appreciably. Slight increases in absorption at 8.4 and $10.3 \mu$ were noted when samples containing 7.25-percent peroxide were vulcanized for $24 \mathrm{hr}$ at

WAVE NUMBER, $\mathrm{cm}^{-1}$

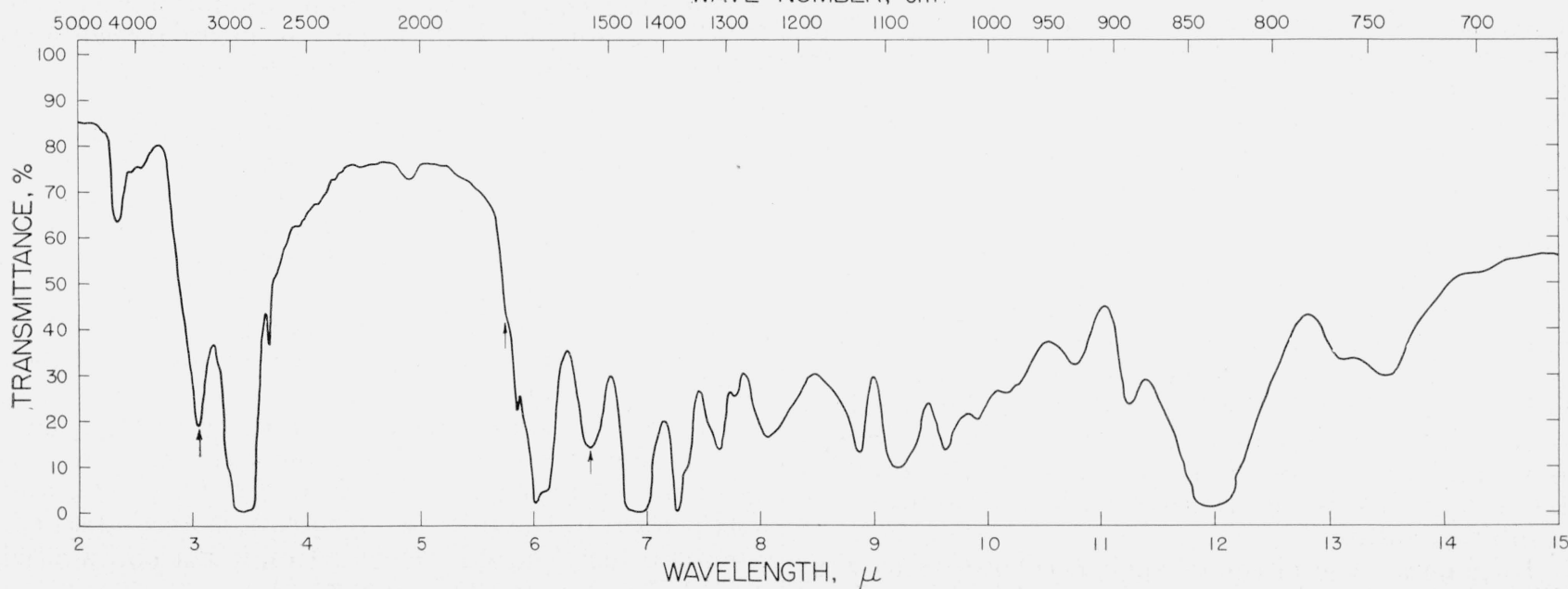

FIGURE 9. Infrared spectrum of natural rubber (pale crepe) vulcanized with 4.0 percent di-tertiary butyl peroxide for $21 / 2$ hr at $135^{\circ} \mathrm{C}$. 
$135^{\circ} \mathrm{C}$. Only a very slight change was noted at $8.4 \mu$ and none at $10.3 \mu$ when these samples wer. vulcanized for $24 \mathrm{hr}$ at $125^{\circ} \mathrm{C}$.

\subsection{Vulcanization With Gamma Rays}

In order to compare the structural changes observed for sulfur vulcanization with those resulting from gamma rays, pressed films of pale crepe rubber alone and with 8-and 15-percent sulfur were exposed to a gamma-ray source of 50-curies strength for $120 \mathrm{hr}$ (exposure dose of $10^{6}$ to $10^{7}$ roentgens) in air and under a vacuum. This exposure is sufficient to cause gelation. The treated specimens were quite sticky and some of them became too thick to give satisfactory spectra.

The changes occurring in the sample containing no sulfur when irradiated in air appear to be the same as those resulting from compounding with peroxide as indicated in figure 9 . For the specimens containing no sulfur and vulcanized in a vacuum and for the samples containing 8- and 15percent sulfur vulcanized either in air or in a vacuum, the spectra were not sufficiently satisfactory to estimate the status of the bands at 3.05 and 6.5 $\mu$; however, the band at $5.75 \mu$ did not seem to be reduced. None of the specimens showed any evidence of conjugation. Because of an incomplete spectrum, the status of the band at $10.4 \mu$ could not be determined for the specimen containing no sulfur and vulcanized in a vacuum, but in all other cases there was no evidence of a double-bond shift.

Sears and Parkinson [32] and Sears, Parkinson, Sisman, and Towns [33j have exposed Hevea presumably vulcanized and containing sulfur, zinc oxide, stearic acid, benzothiazyl disulfide, and phenyl $\beta$-naphthylamine to gamma radiation (absorption dose of $2.2 \times 10^{9}$ rads). They report a continuation of the double-bond shift already started during vulcanization.

\section{Summary and Conclusions}

Infrared studies have been made of natural rubber vulcanized with sulfur alone and also with sulfur and various accelerators. The spectral change (appearance of band at $10.4 \mu$ ) resulting from the doublebond shift observed by Sheppard and Sutherland [36] was verified for compounds containing 2 percent or more of sulfur. The presence of conjugated double bonds in compounds containing 5 percent or more of sulfur has been indicated spectroscopically for the first time (appearance of band at $6.25 \mu$ ) and supported by chemical evidence obtained from studies performed with squalene-sulfur reaction product and maleic anliydride. Conjugation presumably results from either two double-bond shifts, or the introduction of a new double bond. Sheppard and Sutherland [36] have shown the doublebond shift to be correlated with the amount of combined sulfur.

In general, the effect of such accelerators as zinc dibutyl dithiocarbamate (BZ) and tetramethylthiuram disulfide (TMTD) is to reduce at least the amount of conjugation occurring with a given amount of double-bond shift and hence with a given amount of combined sulfur. Apparently these accelerators either prevent the formation of the conjugated double bonds or react to remove them after they are formed. Accelerated compounds also show evidence of reduced absorption due to carbonyl groups and possible increased absorption due to $\mathrm{OH}$ groups as the most likely structures.

Compounds eured with TMTD alone, peroxides, gamma rays, or sulfur dioxide and hydrogen sulfide (Peachey process) do not show evidence of the double-bond shift or of conjugation. They do show a possible decrease in carbonyl structures, and in the case of the last three, possible increased absorption due to $\mathrm{OH}$ and ionized carboxyl groups. Again, the structures named seem to be the most likely ones involved.

Apparently, the double-bond shift and the resulting conjugation are primarily phenomena related to the use of elemental sulfur. The other vulcanization systems studied evidently involve different mechanisms.

There is, during sulfur vulcanization, an increase in the intensity of the band near $6.1 \mu$ relative to that of the band at $6.0 \mu$. This change in relative intensity is noticeable with 12-percent sulfur and increases with increased sulfur content. In rubbersulfur vulcanizates, at least, the band near $6.1 \mu$ has been resolved into a doublet with one absorption at $6.10 \mu$ and the other at $6.13 \mu$.

The fact that the double-bond shift, conjugation, etc., were observed spectroscopically in this work only with certain minimum quantities of sulfur or times of vulcanization, does not imply that they do not actually occur with less sulfur or shorter times of vulcanization. It is only reasonable to assume that they are a continuing part of the over-all vulcanization reaction and that the condition of occurrence of the bands results from their absorptivity and the particular method of spectroscopic study employed.

It is well-known that rubber-sulfur compounds, accelerated compounds, and compounds cured with TMTD alone (all containing the usual percentages of compounding ingredients) are increasingly resistant to aging in the order named. If the present studies can indeed be extrapolated to the smaller percentages of compounding ingredients usually employed, the concentration of conjugated double bonds should also decrease in the same order. Since conjugated double bonds are known to be highly reactive, it is reasonable to assume that there should be some relationship between the ease of oxidation and the concentration of conjugated double bonds in the compound.

Preliminary observations bave revealed that, as a sulfur-vulcanized film of rubber oxidizes, the appearance of absorption bands of $\mathrm{C}=\mathrm{O}, \mathrm{C}-\mathrm{O}$, and $\mathrm{OH}$ groups in the infrared spectrum is accompanied, among other things, by a reduction in the conjugated double-bond absorption at $6.25 \mu$.

It should be noted that the interpretation of the 
band at $10.4 \mu$, as discussed in this article is different from that proposed by Glazebrook and Saville [21], and Bateman, Glazebrook, Moore, and Saville [2]. These authors suggest that this band is due to substituted tetrahydrothiophenes which their studies with small molecules have indicated are formed during vulcanization. These tetrabydrothiophenes are reported to have bands near 10.5 to $10.6 \mu$ and one of them also is reported to have a band at $10.44 \mu$. Ebonite containing 32-percent sulfur and squalenepolysulfide residue from distillation of the reaction product are also reported to have bands in this region in contrast to the results obtained under the conditions employed in the present work. It should be noted that the wavelength of the band observed at $10.4 \mu$ in the present work is shifted to longer wavelengths with increased sulfur content and occurs at $10.45 \mu$ with 25 -percent sulfur. This general trend is in agreement with the findings of Sheppard and Sutherland [36]. Furthermore, the spectrum of the squalene-sulfur reaction product in figure 5 has a shoulder at $10.5 \mu$. It may be that the tetrahydrothiophenes produce the bands at the longer wavelengths and that the band at the shorter wavelengths near $10.4 \mu$ is actually due to a shifted double bond. Perhaps the tetrahydrothiophenes form at a late stage of the reaction or under conditions of bigher concentration of sulfur. In this connection Craig [8] has shown that tetrahydrothiophene itself does not react with maleic anbydride when the two are heated at $125^{\circ} \mathrm{C}$ for $90 \mathrm{~min}$. Thus, the changes observed on reacting the squalene-sulfur reaction product with maleic anhydride, including removal of the band at $6.25 \mu$ and a possible decrease in the intensity of the band at $10.4 \mu$, were probably not due to reaction with tetrabydrothiophenes. In the absence of some other interpretation, it is assumed that these changes are due to reaction with a conjugated bydrocarbon system.

The authors are indebted to F. H. Stross of the Shell Development Co., Emeryville, Calif., for supplying the purified squalene used in this work: and to Edmund J. Blau, formerly of the Bureau and now with the Applied Physies Laboratory, Johns Hopkins University, Silver Spring, Md., for his assistance in the Raman studies.

\section{References}

[1] H. J. Backer and Th. A. H. Blaas, Rec. trav. chim. 61, $785(1942)$

[2] L. C. Bateman, R. W. Glazebrook, C. G. Moore, and R. W. Saville, Proceedings of the third rubber technology conference, p. 298 (W. Heffer \& Sons, Ltd., Cambridge, London, 1954); Rubber Chem. and Technol. 30, 397 (1957).

[3] N. Bekkedahl, F. A. Quinn, Jr., and E. W. Zimmerman, J. Research NBS 40,1 (1948); Rubber Chem. and Technol. $\mathbf{2 1}, 701$ (1948).

[4] G. F. Bloomfield, J. Chem. Soc. 1547 (1947); Rubber Chem. and Technol. 22, 348 (1949).

[5] G. F. Bloomfield, J. Polymer Sci. 1, 312 (1946); Rubber Chem. and Technol. 20, 360 (1947).

[6] G. F. Bloomfield and R. F. Naylor, Proceedings of the XIth International congress of pure and applied chemistry, Vol. II, p. 7, Organic Chemistry, Biochemistry (London, 1947).
[7] M. Braden, W. P. Fletcher, and G. P. MeSweeny, Transactions of the institution of the rubber industry 30, 44 (1954); Rubber Chem. and Technol. 28, 190 (1955).

[8] David Craig, B. F. Goodrich Research Center (private communication).

[9] J. Dale and T. Artun, Acta Chem. Scand. 10, 439 (1956). [10] W. G. Dauben and H. L. Bradlow, J. Am. Chem. Soc. $\boldsymbol{7 4}, 5205$ (1952).

[11] W. G. Dauben, H. L. Bradlow, N. K. Freeman, D. Kritchevsky, and M. Kirk, J. Am. Chem. Soc. y4, 4321 (1952).

[12] H. L. Dinsmore and D. C. Smith, A, Anal. Chem. 20, 11 (1948); B, Rubber Chem. and Technol. 22, 572 (1949).

[13] B. Ellis and H. Pyszora, J. Polymer Sci. 22, 348 (1956).

[14] E. H. Farmer and C. G. Moore, J. Chem. Soc. 142, (1951) ; Rubber Chem. and Technol. 24, 777 (1951).

[15] E. H. Farmer and F. W. Shipley, J. Chem. Soc. 1519 $(1947)$.

[16] E. H. Farmer and F. W. Shipley, J. Polymer Sci. 1, 293 (1946); Rubber Chem. and Technol. 20, 341 (1947).

[17] L. H. Flett and W. H. Gardner, Maleic anhydride derivatives-Reactions of the double bond (John H, Wiley \& Sons, Inc., New York, N. Y. 1952).

[18] P. J. Flory, Principles of polymer chemistry, p. 454 (Cornell University Press, Ithasa, New York, 1953).

[19] S. D. Gehman, J. Am. Chem. Soc. 5\%, 1382 (1935); Rubber Chem. and Technol. 8, 521 (1935).

[20] S. D. Gehman and H. J. Osterhoff, J. Am. Chem. Soc. 58, 215 (1936); Rubber Chem. and Technol. 9, 275 (1936).

[21] R. W. Glazebrook and R. W. Saville, J. Chem. Soc. 2094 (1954); Rubber Chem, and Technol. 28, 109 (1955).

[22] S. E. Horne, et al., Ind. Eng. Chem. 48, 784 (1956); Rubber Chem. and Technol. 29, 687 (1956).

[23] E. Kindscher, The vulcanization of rubber, The science of rubber, edited by K. Memmler (Rheinhold Publishing Corp., New York, N. Y., 1934).

[24] M. C. Kloetzel, Diels-Adler reastion with maleic anhydride, Organic reactions Vol. IV, edited by $R$. Adams, et al. (John Wiley \& Sons, Inc., New York, N. Y., 1948).

[25] J. Mann, J. Rubber Research 18, 79 (1949).

[26] A. T. MePherson, BS J. Research 8, 751 (1932); Rubber Chem. and Technol. 5, 523 (1932).

[27] D. E. Roberts and L. Mandelkern, J. Am. Chem. Soc. y.,781 (1955); Rubber Chem. and Technol. 28, 718 (1955).

[28] G. Salomon and A. Chr. van der Schee, J. Polymer Sci. 14, 181 (1954); Rubber Chem. and Technol. 28, 213 (1955).

[29] G. Salomon, A. Chr. van der Schee, J. A. A. Ketelaar, and B. J. van Eyk, Discussions Faraday Soc. 9, 291 (1950); Rubber Chem. and Technol. 25, 265 (1952).

[30] R. A. Saunders and D. C. Smith, J. Appl. Phys. 20, 953 (1949)

[31] W. C. Sears, J. Appl. Phys. 12, 35 (1941); Rubber Chem. and Technol. 14, 572 (1941)

[32] W. C. Sears and W. W. Parkinson, Bull. Am. Phys. Soc. 1 (II), No. 4, 203 (1956).

[33] W. C. Sears, W. W. Parkinson, O. Sisman, and R. L. Towns, Oak Ridge National Laboratory, Solid state division semiannual progress report for period ending February 29, 1956, ORNL-2051 p. 16.

[34] N. Sheppard, Diseussions Faraday Soc. 9, 331 (1950).

[35] N. Sheppard and G. B. B. M. Sutherland, Trans. Faraday Soc. 41, 261 (1945); Rubber Chem. and Technol. 19, 66 (1946)

[36] N. Sheppard and G. B. B. M. Sutherland, J. Chem. Soc. 1699 (1947); Rubber Chem. and Technol. 21, 799 (1948).

[37] F. W. Stavely and Coworkers, Ind. Eng. Chem. 48, 778 (1956); Rubber Chem. and Technol. 29, 673 (1956).

[38] H. W. Thompson and P. Torkington, Trans. Faraday Soc. 41, 246 (1945); Rubber Chem. and Technol. 19, $46(1946)$.

Washington, June 7, 1957. 